\title{
Meaningful learning in medical science by self-directed approach of - Concept mapping
}

\author{
Leena Chand $^{1}$, K. Sowmya ${ }^{2, *}$, Santhi Silambanan ${ }^{3}$, Manikandan $^{4}$ \\ ${ }^{1}$ Asstistant Professor, ${ }^{2}$ Associate Professor, ${ }^{3}$ Professor, ${ }^{4}$ Associate Professor, Dept. of Biochemistry, Sri Ramachandra Medical \\ College \& Research Institute, Chennai, Tamil Nadu, India
}

*Corresponding Author:

Email: sowmyasathyan@yahoo.co.in

\begin{abstract}
Introduction: Concept mapping is an innovative approach that helps the learner to organize knowledge for a better mental picture. Students should be life-long meaningful learners to adapt to the rapid changing science and apply it in practicing medicine. The concept map may be regarded as an image displaying detailed study of a case or problem through various concepts and by linking them with the key words which enables the learners to do a cognitive analysis. This way of approaching basic science subjects in medical education will definitely improve the meaningful learning (Asubel, 1968). The objective of this study was to introduce concept map as a mode of learning involving various important topics of basic medical sciences subjects and evaluate its usefulness and acceptability among students in improving their understanding of the given topics.

Materials and Methods: Participants are first year MBBS students $(n=250)$ from Sri Ramachandra Medical college and Research Institute; they were divided into small groups of 20-22. Students were evaluated with pretest and post-test performance along with a feedback which were collected and evaluated at the end of the project.

Result: Students subjected to this newer learning method showed a highly significant positive result $(\mathrm{p}<0.001)$.

Conclusion: The introduction of concept- mapping in learning methodology resulted in better understanding of a topic and correlation between all basic courses by the students. It also helps in learning through vertical integration between basic and clinical sciences.
\end{abstract}

Keywords: Concept Map.

\section{Introduction}

Understanding and retaining the concepts in medicine by medical students is a difficult task. In the phase one of MBBS undergraduate curriculum in India the students usually give maximum emphasis on the basic sciences subjects such as Anatomy, Biochemistry and Physiology by attending various theory and practical classes. Theory classes are usually held at lecture halls where the teacher talks on a topic for about an hour using the latest audio-visual technologies. Evidence suggests that the subject taught to students at theory classes seems to have lesser impact in terms of understanding the concepts with utmost clarity and it will retain for a short time in the brain. Rapid changes in the science of medicine and the practice of medical education, there is a strong desire to educate competent practitioners in a way to equip them with necessary skills and competencies to meet the needs of the society in general. ${ }^{1,2}$ In this regard, medical students must be trained based on meaningful and integrated approaches so that they will get the ability to understand and relate relevant medical concepts by linking them to prior knowledge. Critical thinking, clinical reasoning, and clinical problem solving are of great significance in the medical education as medical students typically need additional abilities to improve their clinical skills as a part of bedside learning. So the medical educators should emphasize more on the development of meaningful and self-directed learning among medical students. ${ }^{2,3}$ In medical education, it is always a challenge for educators to link the basic science contents with clinical scenarios for the students have limited or no clinical exposure. Therefore, helping students to learn in a meaningful and integrated way can be an efficient strategy to enhance long-term retention and deeper understanding among medical students. ${ }^{4,5}$ So it becomes important for a teacher to adapt newer teaching methodologies which can supplement all type of learners so that the slow learners can also be at par with their counterparts. One such way or method of active learning is "concept mapping".

Concept mapping is a technique that is helping students to build useful mental frame work. Concept mapping, initially proposed by Joseph Novak, is an innovative approach that helps the learner to organize knowledge. ${ }^{6}$ Concept maps communicate knowledge graphically instead of relying on lengthy textual explanations. Concept maps as a teaching and learning strategy support meaningful learning. Meaningful learning which can be defined as a condition that information is understood very well by the learner. At this end of the spectrum, the conceptual meaning of the new information is clear and the new knowledge can be linked to related concepts already known to the learner and this leads to self-directed learning. Evidence shows that meaningful learning is more efficient and lasting ${ }^{4,7}$ because of the integration and linkages made with prior knowledge and this facilitates the transfer of new information into long term memory. 


\section{Objectives}

The objective of this study was: 1) To introduce concept map as a mode of learning involving various important topics of basic medical sciences subjects; 2) To evaluate its usefulness in different important areas of basic sciences; 3 ) To assess its acceptability among students in improving their understanding of the given topics by feedback analysis.

\section{Materials and Methods}

It is a cross-sectional study conducted at SRMC \& RI, CHENNAI. The current first-year MBBS students $(\mathrm{n}=250)$ admitted during the academic year of 20142015 took part in the project of making concept map. The batch of students was divided into 12 small groups with 20-21 students in each group. Each group was assigned with a topic allotted and chosen by the respective groups by lot system. Each group was assigned with facilitators from all the three departments for coordination and to guide the students for making their allotted topics related concept maps.

Table 1

\begin{tabular}{|c|l|}
\hline S. No. & \multicolumn{1}{|c|}{ Topics } \\
\hline 1 & Edema \\
\hline 2 & Disorders of thyroid \\
\hline 3 & Acute coronary syndrome \\
\hline 4 & Bronchial asthma \\
\hline 5 & Diabetes mellitus \\
\hline 6 & Peptic ulcer \\
\hline 7 & Jaundice \\
\hline 8 & Hypertension \\
\hline 9 & Cushing's syndrome \\
\hline 10 & Steatorrhoea \\
\hline 11 & Nutritional anemia \\
\hline 12 & Renal failure \\
\hline
\end{tabular}

All the topics allotted (Table 1) were already covered for them as large group lectures. So immediately after allotting topics respective faculties of each group conducted a small test (pre-test) on specific questions related to that topic. Sufficient time was given for each group for interaction and clearing their exiting doubts regarding preparation of concept maps. The various stages proposed by Novak and Canas ${ }^{7}$ such as

1. Brainstorming stage; 2. Organizing stage; 3. Layout stage; 4. Linking stage; 5. Revising and 6. Finalizing stage were followed during concept mapping with few changes for convenience. After a time of 2 weeks all the groups were ready with their posters and displayed as exhibition on a particular day.

\section{Two of manuscripts of Concept Mapping prepared by students:}
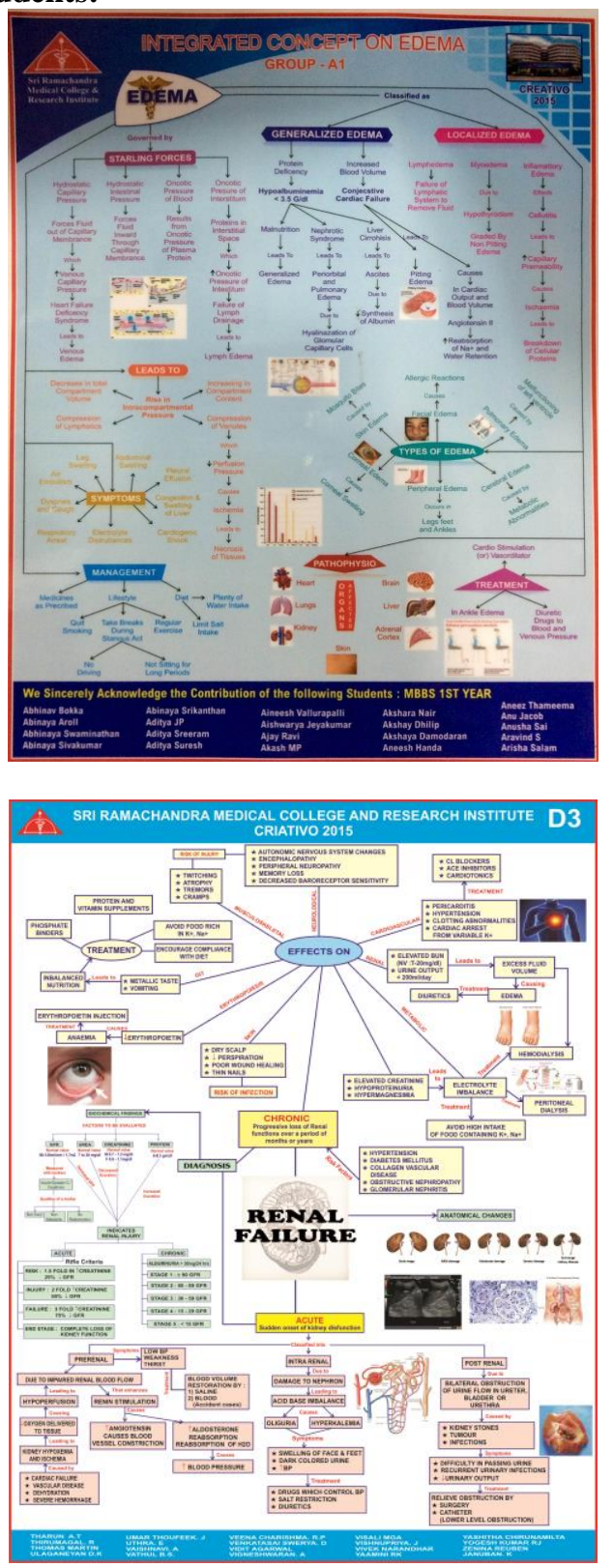

All the concept maps prepared by the small groups were judged by senior faculty members of other disciplines and not belonging to the three basic science subjects. Prior information about the topics was already informed to all the judges. They evaluated all the posters based on the given criteria such as: 1 . Organization; 2. Links \& Resources; 3. Skills. (Table 2) 
Table 2

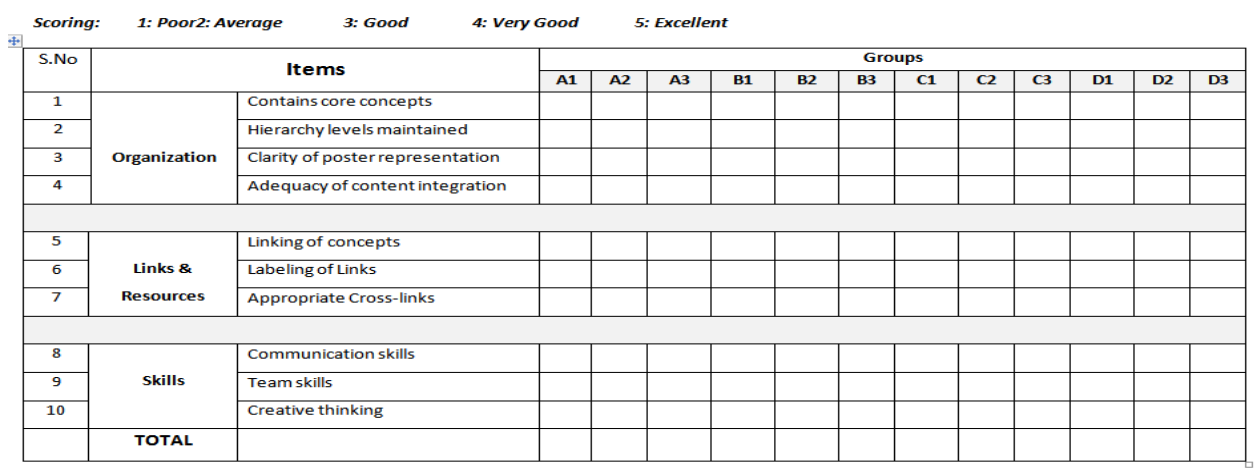

Judges Comments:

Signature

Another test was conducted for each group with same questions as after the presentation (post-test). At the end of the project feedback was also obtained from the students.

The performances of the students were assessed by comparing their test scores in two written tests. The methodology of the tests included multiple choice questions (MCQs), fill in the blanks, and short answer questions (SAQs). Each test contained between 10- 15 questions, and questions were based on the topic given to each group. Feedback was obtained from students about their perception, usefulness, understanding and overall impact through a 7- items, 5- points Likert scale questionnaire. (Table 3)

Table 3

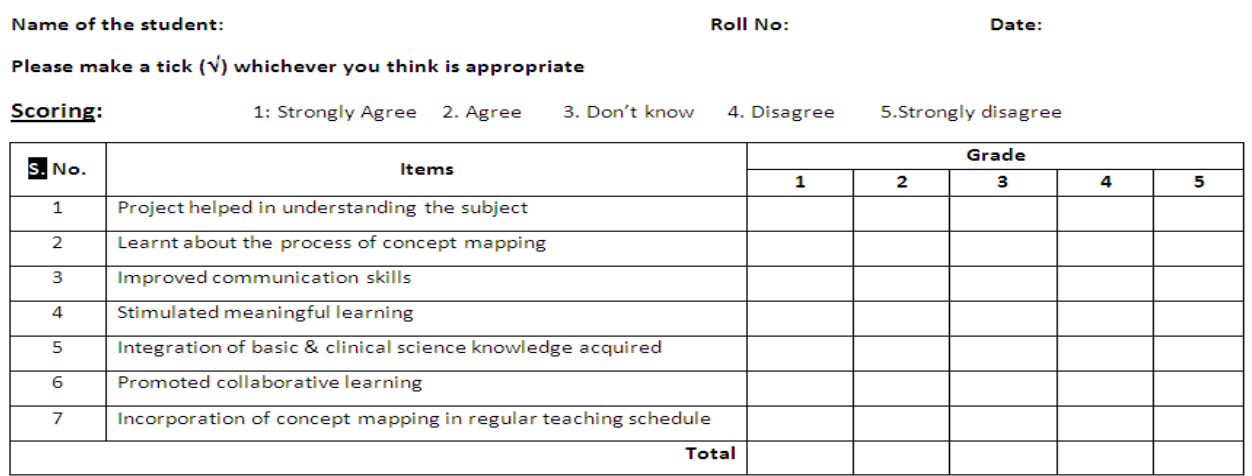

Other comments if any:

\section{Result}

Statistical analysis was done by applying Paired - $t$ - test. The mean difference between pre-test $(3.27 \pm 1.204)$ and post test $(4.50 \pm .702)$ showed that there is a statistically significant increase of 1.23 (95\% CI $1.376-1.071, \mathrm{t}=$ 15.790, p value <.000) (Graph 1).

Graph 1: Graph showing the performance of the students in pre and post test

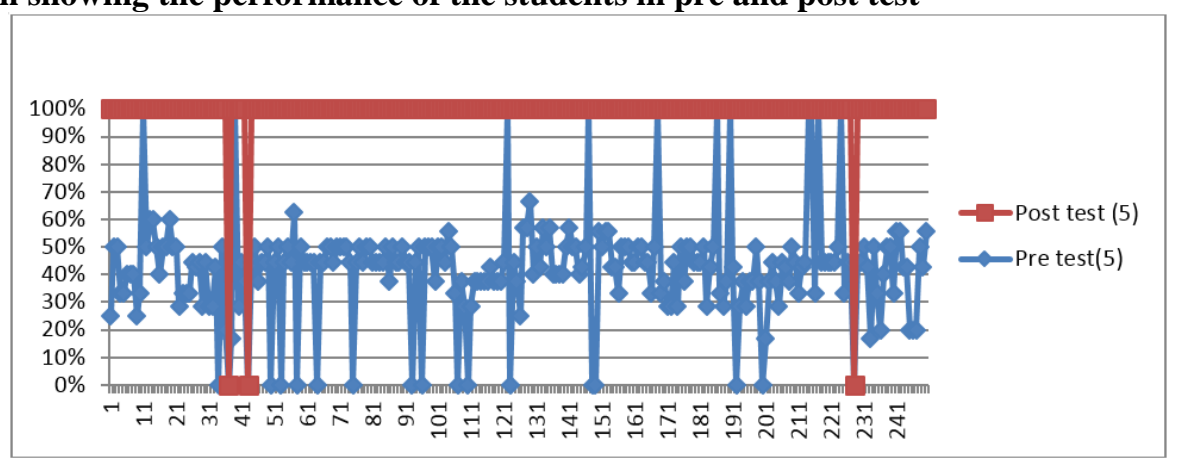


On analyzing the students' feedback (Table 4) it showed that the teaching intervention definitely improves the understanding of subject knowledge by the students as $58 \%$ showed improved performance.

Table 4: Percentage analysis of students' feedback

\begin{tabular}{|c|l|c|c|c|c|c|}
\hline S.No. & \multicolumn{1}{|c|}{ Items } & \multicolumn{1}{|c|}{ Grade } \\
\hline & \multicolumn{1}{|c|}{$\mathbf{1}$} & $\mathbf{2}$ & $\mathbf{3}$ & $\mathbf{4}$ & $\mathbf{5}$ \\
\hline 1 & Project helped in understanding the subject & 62.2 & 33.7 & 4.1 & 0 & 0 \\
\hline 2 & Learnt about the process of concept mapping & 46.5 & 46.9 & 5.6 & 0 & 1 \\
\hline 3 & Improved communication skills & 42.7 & 46.5 & 8.8 & 1 & 1 \\
\hline 4 & Stimulated meaningful learning & 47.8 & 43.5 & 7.7 & 0 & 1 \\
\hline 5 & $\begin{array}{l}\text { Integration of basic \& clinical science knowledge } \\
\text { acquired }\end{array}$ & 48.2 & 41.4 & 8.6 & 1.8 & 0 \\
\hline 6 & Promoted collaborative learning & 46.7 & 41.4 & 8.6 & 2.3 & 1 \\
\hline 7 & $\begin{array}{l}\text { Incorporation of concept mapping in regular } \\
\text { teaching schedule }\end{array}$ & 41.5 & 37.7 & 15 & 3.8 & 2 \\
\hline
\end{tabular}

Scoring 1: Strongly Agree 2. Agree 3. Don’t know 4. Disagree 5. Strongly disagree

\section{Chart 1}

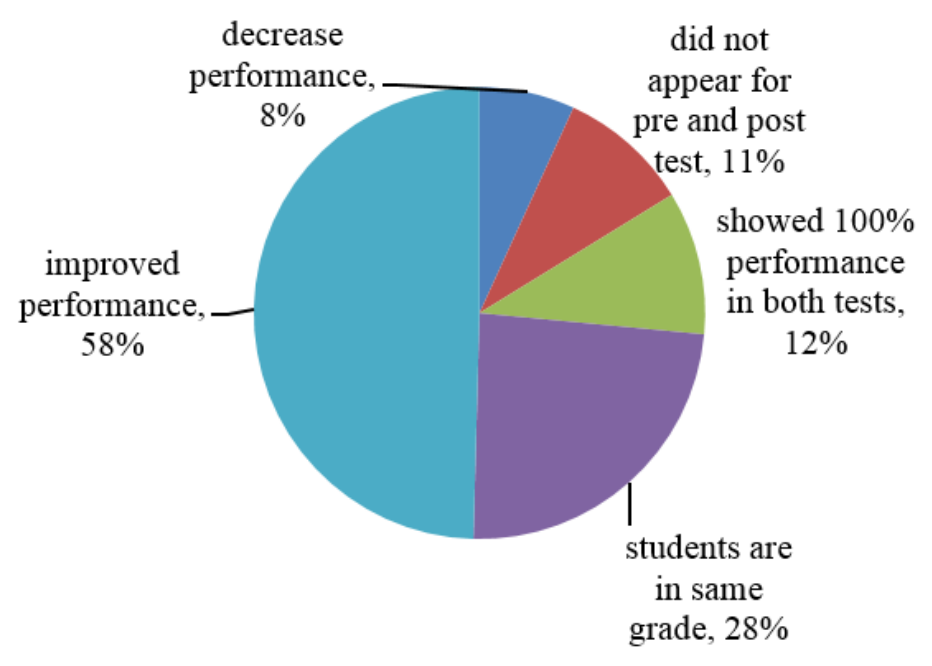

So it showed the newer method of learning through concept mapping will not only increase the understanding on the subject matter it also fulfills the integration of basic and clinical science as we found in our result (Chart 1).

\section{Discussion}

Concept Map is a concise 2D model displaying a constellation of various concepts of a particular topic and linking them through schematic presentations. The linkages provide the student with new information of a topic which the student is already familiar with and understands that the new information provided will be meaningful. Moreover the students acquire the concept of a topic from the regular lecture class and concept map shows how their concept has a continuum of learning by extending it to laboratory/clinical applications. Andwe got same positive significant finding in our study. Various other researches also show similar results stating that concept map is an innovative way to provide instructions and provides a platform for the learners to develop a more analytical approach to topics and enables them to clinically integrate their knowledge of basic sciences. ${ }^{8-10}$
$66.2 \%$ students gave the feedback that this type of project helped in understanding the subject, $47 \%$ students learnt about the process of concept mapping by doing this project. Students also gave the written feedback as suggestion that during preparing the concept map work, there was a marked improvement in inter-personal communication among them. It also stimulated the integration of all the three basic science subjects during $1^{\text {st }}$ MBBS with clinical science knowledge acquired. Students suggested for, Incorporation of concept mapping in regular teaching schedule.

This study showed $58 \%$ improved performance, $28 \%$ are in same grades, $12 \%$ showed $100 \%$ performance in both tests, $11 \%$ did not appear pre or post test and the decreased performance in $8 \%$ of participants may be attributed to their lack of interest and involvement in presentation of respective topics .The students were definitely benefitted by doing the 
concept map project, which improved the performance and understanding. Also, the participants in the innovative curriculum felt that the teacher's role as facilitator is the key factor for the proper conducting of these concept-mapping sessions in small groups which is supported by studies of - Mc Gaghie WC et al and Pinto A. ${ }^{11,12}$

At the first stage the topics selected were distributed to the small groups and details of the topics were discussed between facilitators and students. The organizing stage included a deeper analysis of the medical problem related to the topic. The information were listed out and integrated in layout stage. The basic biochemical concepts were linked to the clinical problems in linkage stage. Revising of the existing knowledge and attempt to gain insights to new knowledge were done in revising and finalizing stage. There was also exchange of information and ideas among the students during gallery walk. The whole exercise showed that concept mapping is an ideal approach for meaningful learning in medical education.

Learning in a meaningful way means that medical students, residents, and practicing physicians actively seek out ways to link new information and experience with what they already know, thus creating an organized knowledge base leading to the development of adaptive expertise in medical practice.

\section{Conclusion}

Concept mapping can be introduced in the teaching \& learning methodology as an useful modality for learning by students. It helps in correlating all basic MBBS courses and integrates vertically with clinical sciences also. Concept mapping improves creativity of the students by enhancing cognitive analysis of problems. It is well accepted by the learners as it improves the understanding on subjects/topics.

\section{References}

1. Ausubel, D. P. (1968) Educational Psychology: A Cognitive View. New York: Holt, Rinehart and Winston

2. Anderson, O. R. (1992). Some interrelationships between constructivist models of learning and current neurobiological theory, with implications for science education. Journal of Research in Science Teaching, 19(10), 1037-58.

3. Alvarez, G \& Montoya, F.,(2012) Using concept maps to improve scientific communications. Engineering.Novak, J., Concept Maps: What The Heck Are These?

4. Laight DW. Attitudes to concept maps as a teaching/learning activity in undergraduate health professional education:influences on preferred learning styles. Med Teach 2004;26:229-33.

5. Dabbagh N. Concept mapping as a mind tool for criticalthinking. J Comput Teach Educ 2001;17:16-24.

6. Joseph D. Novak, (1990) Concept mapping: A useful tool for science education. Journal of research in science teaching. Vol.27.No.10, pp.937-49.

7. Novak, J. D. and A. J. Cañas (2006b): The Theory Underlying Concept Maps and How to ConstructThem.
Pensacola, FL: Florida Institute for Human and Machine Cognition.

8. Rendas A, Fonseca M, Pinto PR. Toward meaningful learning in undergraduate medical education using concept maps in a PBL pathophysiology course. Adv Physiol Educ 2006;30:23-9.

9. Kinchin, I.M. \& Cabot, L.B., 2007. Using concept mapping principles in powerpoint. European journal of dental education: official journal of the Association for Dental Education in Europe, 11(4), pp.194-9. Available at:

10. http://www.ncbi.nlm.nih.gov/pubmed/1793558

11. West DC, Pomerory JR, Park JK, Gerstenberger EA, Sandoval J. Critical thinking in graduate medical education: a role of concept mapping assessment? JAMA 2000;284:1105-10.

12. McGaghie WC, McCrimmon DR, Mitchell G, Thompson JA. Concept mapping in pulmonary physiology using pathfinder scaling. Adv Health Sci Educ 2004;9:225-40.

13. Pinto AJ, Zeitz HJ. Concept mapping: a strategy for promoting meaningful learning in medical education. Med Teach 1997;19:114-21.

14. AlexandreB.Se, Renato M. Passos, Andre H. Ono and Marcelo Hermes-Lima. 2007. "The use of multiple tools for teaching medical Biochemistry". AdvPhysiol Educ.32:38-46. 